\title{
Bioconcentration and Antioxidant Status Responses in Zebrafish (Danio Rerio) Under Atrazine Exposure
}

\author{
Abeer Ghazie A. Al-Sawafi and Yunjun Yan
}

\begin{abstract}
The present study was planned designed to investigate the chronic impacts of herbicide atrazine exposure on stress biomarkers acetylcholinesterase activity ( $\mathrm{AChE})$ and oxidative stress responses in brain of zebrafish (Danio rerio), and determine the bioconcentration of atrazine in whole body of fish. Chronic exposure to atrazine unveiled a markedly discourage in the activity of AChE. However, significant increase in the activities of catalase (CAT) and superoxide dismutase (SOD) and both influenced by atraizine, and CAT was over sensitivity to atrazine compared with SOD. The highest bioconcentration factor (BCF) of atrazine in the fish treated was $\left(12.8543 \times 10^{4}\right.$ and $\left.13.5891 \times 10^{4}\right)$ after $24 \mathrm{~h}$ exposure to $\left(0.957\right.$ and $\left.1.913 \mathrm{mg} \mathrm{L}^{-1}\right)$ and $13.238 \times 10^{4}$, after $25 \mathrm{~d}$ exposure to $0.638 \mathrm{mg} \mathrm{L}^{-1}$ of atrazine respectively. This study showed that the zebrafish have ability to bioaccumulate of the herbicide atrazine rapidly. atrazine accumulation in zebrafish has a private importance due to the implication of atrazine in chronically health problems, as well as the information contained in our study is useful for understand the mechanism of atrazine induced oxidative stress in fish.
\end{abstract}

Index Terms-Atrazine, stress biomarkers, bioconcentration factor, zebrafish.

\section{INTRODUCTION}

The presence of pesticides in the environment has caused significant social and scientific development anxiety worldwide, as their all over the world extensive usage can create potential risks to the environment and human health, as they can easily pollute bodies of water, resulting in extensive damage to non-target species, including fish [1]. Fish representing as bio-indicators of environmental contamination and may play an important role in the evaluation of the potential risk of pollution in aquatic environment, from they may directly exposed to chemicals caused by agricultural output through runoff or indirectly by food chain of ecosystem, this may reflect the biological influences of environmental contamination in water [2]. The zebrafish (D. rerio) is a small equatorial freshwater fish that has a great tolerance for a wide range of breeding circumstances has been employed as an experimental species in the intensive studies of many other scientists, from the 1980s. Particularly in recent years, numerous studies have shown the identified benefits of hiring of zebrafish in environmental toxicological studies [3]. The use of

Manuscript received April 22, 2013; revised June 20, 2013.

Abeer Ghazie A. Al-Sawafi is with the College of Life Science and Technology, Huazhong University of Science and Technology, Wuhan 430074, Hubei, P. R. China (e-mail:abeerghazie@ yahoo.com).

Yunjun Yan is with the College of Life Science and Technology, Huazhong University of Science and Technology, Wuhan 430074, Hubei, P. R. China (e-mail: yanyunjun@hust.edu.cn). herbicides to control weeds has been admitted, and its frequent applications as a part of farming practices worldwide. Sadly, the random use of these herbicides to improve agricultural output, careless handling, accidental spillage or discharge of untreated effluents into natural waterways may have adverse impacts on non-target organisms, private fish and other aquatic objects and may contribute to long term impacts in the environment [4]. Atrazine is one of the more widely used herbicides found in the rural environments. It is widely used on corn, sorghum, sugarcane, pineapples, and fairly on landscape vegetation, As well as to control aquatic weeds has implementation in fish management where they are used in aquatic habitats particularly rice fields and some fish farms. It is a commonly used that prevents electron transfer mechanisms of photosystem II in objective plants [2]-[5]. Atrazine also been classified as moderately toxic to aquatic species, mobile in the environment, it is from more pesticides observed in creeks, rivers, ponds, reservoirs and ground waters [6]. It contains a comparatively high proportion of water-soluble $\left(32 \mathrm{mg} \mathrm{L}^{-1}\right)$, which assists in its penetration of ground water because of its high mobility through soil [5]. In contrast, WHO [7] noted that atrazine may be degraded in surface water by photolysis and microorganisms and the half-life of 20 - 50 days at $20-25^{\circ} \mathrm{C}$ was found in vitro circumstances and increasing at lower temperatures. The properties of atrazine are summarized in Table 1. Sublethal impacts with biochemical changes of fish tissues may occur with long term exposure to levels of lowest from $2 \mathrm{mg} \mathrm{L}^{-1}$ of atrazine [4]. Several writers have mentioned the effect of atrazine on the physiology, metabolism, growth and reproduction of aquatic organisms, special on fishes [8] and also can cause impaired embryonic growth [3]. Hence, it is necessary to identify certain parameters used in the assessment of environmental hazards of pesticides, as the degree of accumulation and stress biomarkers of atrazine in aquatic objects. The study on the environmental hazards allows strategies to be development towards secure fishing managing. The implementation of these strategies makes possible the survival of sanitary fish living on aquatic regions close to the crops where atrazine is used [9]. Therefore, impacts of contaminants bioaccumulation on fish are assessed by chronic toxicity test, and because the stress response of fish is similar in several ways to that which happening in higher vertebrates [10]. The aim of this study was to investigate the bioconcentration level of herbicide atrazine in fish body during sublethal exposure .Then, to evaluate the impact on some biochemical indices in zebrafish (Danio rerio). In order to obtain a better understanding of the potential environmental implications of atrazine and to enable 
appropriate instructions to be drawn up for the safe application of this herbicide in the field.

\section{MATERIALS AND METHODS}

\section{A. Animals and Experimental Design}

Zebrafish (3.1 $-4.6 \mathrm{~cm}$ in length, 0.295 to $0.847 \mathrm{~g}$ in weight) used as object for sublethal test was purchased from the Institute of hydrobiology, Chinese academy of Science, Wuhan, P. R. China. They were fed twice a day with commercial fish food. The atrazine (2-chloro -4-(ethylamino) -6- (isopropylamino) - S-triazine); $97 \%$ purity was obtained from Xingyinhe Chemical Engineering Co. The $96 \mathrm{~h} \mathrm{LC50}$ of atrazine was $\left(9.567 \mathrm{mg} \mathrm{L}^{-1}\right)$ by use of Finney's Probit Analysis according to [13] and $1 / 15_{\text {th }}, 1 / 10_{\text {th }}$ and $1 / 5_{\text {th }}$ of the $\mathrm{LC}_{50}$ values were $0.638,0.957$ and $1.913 \mathrm{mg} \mathrm{L}^{-1}$ respectively, taken as sublethal concentrations for this study. Fish samples were divided into four groups, each containing 100 fishes in an aquarium of 40-liter capacity. Group I was held in tap water as control and other groups were exposed to sublethal concentration for 5, 10, 15, 20 and 25 days. At the end of each exposure period, the fish were removed from each tank to dissect.

\section{B. Bioconcentration Test}

Bioconcentration of attrazine in the whole body tissue of zebrafish was measured by determining the herbicide atrazine in water. After filtrating it using $0.22 \mu \mathrm{m}$ filtration membrane and stored at $4^{\circ} \mathrm{C}$, the samples were analyzed using high-performance liquid chromatography (HPLC). Pesticide were extracted from fish tissue according to the method described by [14], using whole body of zebrafish except its fins, after cut in small portions with a stainless steel scissors and crushed $2 \mathrm{~g}$ wet weight of sample which that used to extract the pesticides with a quantity of acetonitrile. The sample was homogenized for 1.5 and $1 \mathrm{~min}$, respectively, in vortex mixer before and after $2.00 \mathrm{~g}$ of $\mathrm{MgSO}_{4}$ and $0.50 \mathrm{~g}$ of $\mathrm{NaOAc}$ was added. The sample was centrifuged at $4000 \mathrm{rpm}$ for $5 \mathrm{~min}$. A quantity of $1.0 \mathrm{~mL}$ of supernatant was transferred into a $2 \mathrm{~mL}$ plastic centrifuge tube containing $50.00 \mathrm{mg}$ of PSA and $100 \mathrm{mg}$ of $\mathrm{MgSO}_{4}$, after blended the sample by a vortex, and centrifuged at $8000 \mathrm{rpm}$ for $5 \mathrm{~min}$. Then, the supernatant was transferred into a $2 \mathrm{~mL}$ plastic tube containing $30.00 \mathrm{mg}$ PSA, after blended for $1.5 \mathrm{~min}$ and then centrifuged at $8000 \mathrm{rpm}$ for $5 \mathrm{~min}$, finaly the extract was filtered with a $0.22 \mu \mathrm{m}$ filter and analysed by HPLC. The system SSI 2300-525 HPLC contained: Detector: Variable dual wavelength $525 \mathrm{UV}$ detector; column: Apollo C18 column $(250 \mathrm{~mm} \times 4.6 \mathrm{~mm}, 5 \mu \mathrm{m})$ ALLTECH company; the Series III pump Cschrom Plus chromatography workstation; column temperature: $30^{\circ} \mathrm{C}$. atrazine detections were made in the UV region $(\lambda=254 \mathrm{~nm})$. The composition of mobile phase was acetonitrile (35\%) plus $0.025 \mathrm{M}$ dipotassium hydrogen phosphate $(\mathrm{pH} 3.0$ with acetic acid) (65\%). The flow rate and injection volume for herbicid atrazine was 1.0 $\mathrm{mL} \min ^{-1}$ and $20 \mu \mathrm{L}$, respectively. The retention times for it were $11.08 \mathrm{~min}$. Under the chromatographic conditions, the quantitative determination of pesticides was performed by using external standards. A $1000 \mathrm{mg} \mathrm{L}^{-1}$ stock standard solution of atrazine was prepared by dissolved in $(80 \%$ aceton) and serial dilutions were made and the standard calibration curve was set up as $y=32444 x-4283.2, R^{2}=$ 0.9933 .

Therefore, a calibration curve for atrazine was plotted between peak base area from the chromatogram and different concentrations.

TABLE I: NOMENCLATURE AND PHYSICOCHEMICAL CHARACTERISTICS OF THE HERBICIDE ATRAZINE [11]

\begin{tabular}{ll}
\hline Commune Name & Atrazine \\
Trade names & $\begin{array}{l}\text { Malermais, X-Siprim, Vegfru } \\
\text { Solaro } \\
\text { 2-chloro-4-ethylamino-6-isopropyl } \\
\text { amino- 1,3,5-triazine }\end{array}$ \\
IUPAC name & Triazine, Herbicide \\
Class & crystalline solid, white, colorless \\
Physical state: & \\
Molecular weight: & C8H14CIN5 \\
Chemical formula: &
\end{tabular}

Chemical structure

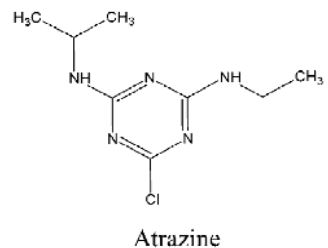

Density:

$1.87 \mathrm{~g} / \mathrm{cm} 3$ at $20 \mathrm{oC}$

Solubility in water:

$30 \mathrm{mg} / \mathrm{L}$

Vapor pressure:

3 x 10-7 mm Hg @ 20o C

Field half life:

60 days

$\operatorname{aEPA} \operatorname{limit}(\mu \mathrm{g} / \mathrm{L})$ :

0.3

${ }^{\mathrm{a}}$ Kulluru [12]

\section{Determination of AChE and Antioxidant Activities}

The brain tissues were collected for biochemical analysis, after homogenized to $1 / 10(\mathrm{w} / \mathrm{v})$ ratio of cold physiological saline solution $\mathrm{NaCl}(0.86 \%)$ using a mortar and pestle, and then, centrifuged at $8000 \mathrm{r} / \mathrm{min}$ for $10 \mathrm{~min}$ in $4{ }^{\circ} \mathrm{C}$, the supernatant was used for biochemical analysis.

AChE activity was determined at $412 \mathrm{~nm}$ wavelength by method of [15]. Acetylcholine iodide and dithiobis nitrobenzoic acid were used as substrates. SOD and CAT activities were measured by method of [16]. The specific activity was defined as units of activity per milligram of protein. Total protein content was quantified by the procedure of [17] at $595 \mathrm{~nm}$ and using bovine serum albumin as standard. And the standard calibration curve was set as $y=0.0051 x-0.0013\left(R^{2}=0.9993\right)$.

Statistical analysis

The data obtained was analyzed statistically by two-way Analysis of variance (ANOVA). The differences between the control and the exposed groups were well checked. The criterion for significance was set at $p<0.05$. Statistical analysis was performed by GraphPad software. The bioconcentration factors $(\mathrm{BCF})$ of atrazine in zebrafish were estimated using the following equation: $\mathrm{BCF}=\mathrm{Cf} / \mathrm{Cw}$ where $\mathrm{Cf}$ is the concentration of toxicant in fish and $\mathrm{CW}$ is the 
concentration of atrazine in the exposure solution

\section{RESULtS}

\section{A. Bioconcentration of Atrazine in Zebrafish}

Based on the results of toxicity, zebrafish were exposed to $0.638,0.957$ and $1.913 \mathrm{mg} \mathrm{L}^{-1}$ of atrazine, and the bioconcentrations of atrazine in fish were detected during different periods (Fig. 1).

The results showed that, for $\left(0.957\right.$ and $\left.1.913 \mathrm{mg} \mathrm{L}^{-1}\right)$ treatments, the $\mathrm{BCF}$ of atrazine in zebrafish increased rapidly shortly after exposure to the chemical, which reached a high level after $24 \mathrm{~h}\left(12.8543 \times 10^{4}\right.$ and $\left.13.5891 \times 10^{4}\right)$ and then declined quickly to a low level after 15 and 25 days. In contrast, the highest BCF of atrazine in fish increased after 25 days in fish treated with $0.638 \mathrm{mg} \mathrm{L}^{-1}$ of the chemical was $13.238 \times 10^{4}$.

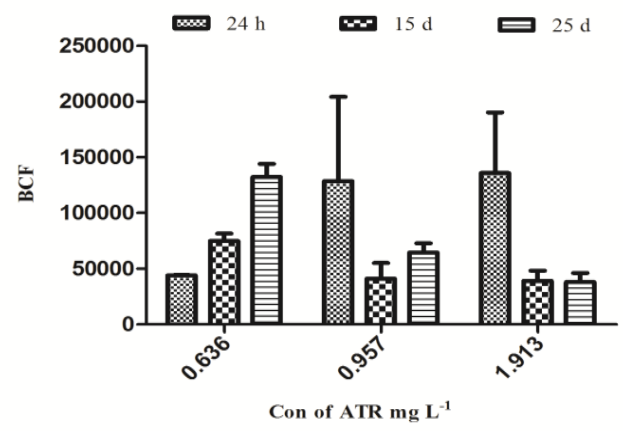

Fig. 1. Bioconcentration factor (BCF) of atrazine exposure to different sublethal concentrations to whole body of zebrafish during $24 \mathrm{~h}, 15$ and 25 days. Values are presented as a mean \pm SD.

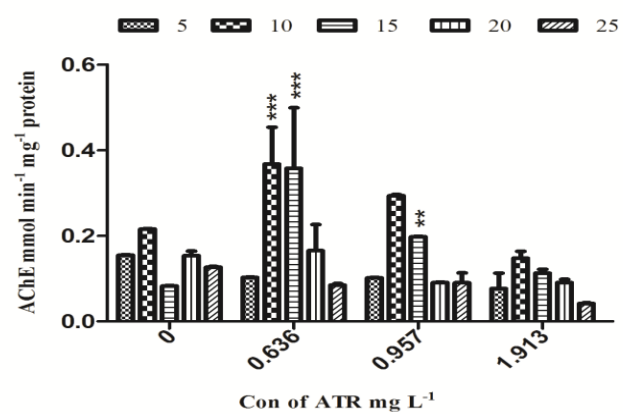

Fig. 2. AChE activities in brain tissues of zebrafish after exposure to different atrazine concentration for 5, 10, 15, 20 and 25 days. Values are presented as a mean \pm SD. The asterisk represents a statistically significant difference when compared with the controls; * at $p<0.05$, ** at $p<0.01$ and $* * *$ at $p<0.001$ levels.

\section{B. Effect of Atrazine on AChE and Antioxidants Activity in Brain Zebrafish}

In brain initially at 5 days (atrazine 0.638 and $0.957 \mathrm{mg} \mathrm{L}^{-1}$ ) doses the AChE level was decreased 66.452 and $65.806 \%$ respectively. But showed sudden slip at $0.638 \mathrm{mg} \mathrm{L}^{-1}$ dose $66.929 \%$ after 25 days. whereas the level of $\mathrm{AChE}$ was a gradual decline at (atrazine 0.957 and $1.913 \mathrm{mg} \mathrm{L}^{-1}$ ) doses 59.091 and $51.969 \%$ after 20 and 25 days when compared with control fish Fig. $2(p<0.05)$.

As shown in Fig. 3, during the progress of the experiment, antioxidant enzymes CAT increased $(p<0.01)$ in a dose and time-dependent manner in brain tissues after 5, 10, 15, 20, 25 days at all instances of atrazine treatment 162.252, 243.115, $187.608,217.459$ and $255.116 \%$, respectively, was higher than that observed in the controls, in zebrafish. the antioxidant SOD activity in brain tissue showed marked increase $(p<0.01)$ after 10, 15 days of atrazine treatment at 0.638 and $0.957 \mathrm{mg} \mathrm{L}^{-1}$ concentrations by (226.121 and $216.309 \%$ ). Whereas, at $1.913 \mathrm{mg} \mathrm{L}^{-1}$, the enzyme activity increased by $110.602,193.645,151.763$ and $139.423 \%$, respectively, after 5, 10, 15 and 20 days, over control values Fig. 4.

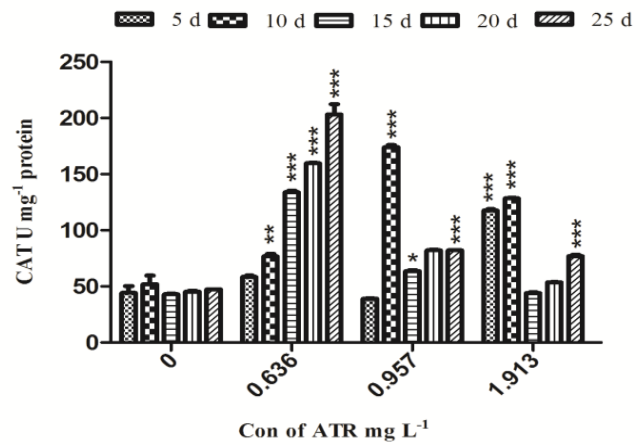

Fig. 3. CAT activities in brain tissues of zebrafish after exposure to different atrazine concentration for 5, 10, 15, 20 and 25 days. Values are presented as a mean \pm SD. The asterisk represents a statistically significant difference when compared with the controls; * at $p<0.05, * *$ at $p<0.01$ and $* * *$ at $p<0.001$ levels.

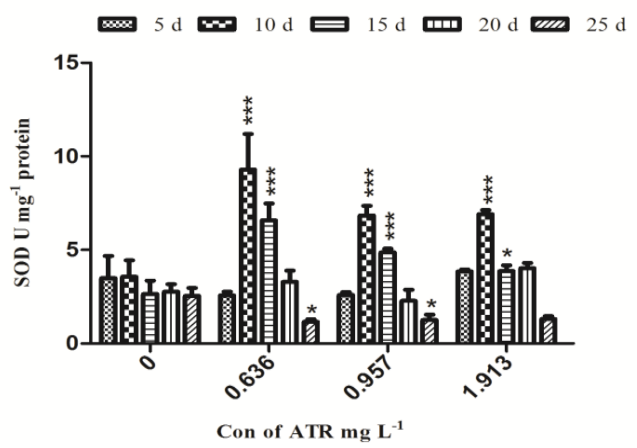

Fig. 4. SOD activities in brain tissues of zebrafish after exposure to different atrazine concentration for 5, 10, 15, 20 and 25 days. Values are presented as a mean \pm SD. The asterisk represents a statistically significant difference when compared with the controls; * at $p<0.05, * *$ at $p<0.01$ and $* * *$ at $p<0.001$ levels.

\section{DISCUSSION}

The bioaccumulation of chemical compounds in aquatic organisms has long been assessed by using indices called the 'bioconcentration factor (BCF) [18]. Aquatic organisms accumulate and maintain some of chemicals when exposed to these chemicals via water and their diet [19]. In this study, we select the BCF value for small fish that plays an important role in the aquatic ecosystem. The study showed that atrazine could be rapidly accumulated in fish shortly after their exposure to a sublethal concentration of atrazine, and the highest BCFs of atrazine in zebrafish were $12.8543 \times 10^{4}$ and $13.5891 \times 10^{4}(24 \mathrm{~h})$ after exposure to 0.957 and $1.913 \mathrm{mg} \mathrm{L}^{-1}$ of atrazine respectively. Outcomes suggested that short periods of atrazine exposure are enough to check the bioaccumulation in fish or other aquatic organisms. our work 
Similar to that reported by Zhao [14] indicated that pyrimorph could be rapidly accumulated in zebrafish shortly after their exposure to a sublethal concentration of pyrimorph, and found the highest BCFs of pyrimorph in fish were $1.07 \times$ $10^{2}(144 \mathrm{~h})$ and $23.1(96 \mathrm{~h})$ after exposure to 2.00 and 0.25 $\mathrm{mg} \mathrm{L}^{-1}$ of pyrimorph respectively. In turn, these concentrations a decrease of the BCF after 25 days can be noted, which may possibly alludes on promoted organizational processes, as for instance metabolisation and excretion, as suggested by Contardo-Jara [20]. In the same time, the larger BCF value was observed in the zebrafish treated at lower concentration $\left(0.638 \mathrm{mg} \mathrm{L}^{-1}\right)$ of atrazine $13.237 \times 10^{4}$ after 25 days. Similarly, exposure to atrazine the larger BCF value was observed in the Carassius auratus with lower concentration of atrazine [21], as well as in Japanese medaka (Oryzias latipes) were exposed to different concentrations of pentachlorophenol (PCP) and 2, 4-dichlorophenol (2, 4-DCP) for 60 days using a continuous flow system, found that the BCF values for both PCP and 2, 4-DCP increased as their aqueous concentrations decreased [18].

The bioconcentration factors in the zebrafish tissues (BCF) in this study were much higher than bioconcentration factors calculated by du Preez and van Vuren, [22] (0.9 to 20.0, in the Tilapia sparrmanii) and Jacomini [23] (8.11 to14.85, in two bivalves species (Anodontites trapesialis and Corbicula fluminea) exposure to atrazine. May be, the smaller fish have highest metabolic rates (per gram of body tissue) and are thus capable to take up chemical material, by food and water, more quickly than larger fish, as proposed by Nussey [24] and rely heavily on species, exposure period, and aqueous concentration of the chemicals [18].

In ecotoxicology, it is highly advised to use cellular and biochemical parameters to evaluate the toxic impacts of chemicals to animals. Because biomarkers can be used to measure the interaction among a biologicalsystem and an ecological agent, which may be chemical, physical, or biological. Discourage or incitement of biomarkers is a well environmental tool to evaluate the exposure and the possible impacts of xenobiotics on objects [25]. The present study attempted to refer to significant impacts of long-term exposure to sublethal concentrations of atrazine pesticide on AChE and antioxidant CAT and SOD activity in the brain of zebrafish.

Can Antioxidant enzymes, whose function is to dispose of oxygen free radicals and protect the organism could indirectly, reflect the alterations of oxygen free radical content in living cells. SOD and CAT protection biomolecules from ROS-mediated harm in vivo. SOD can stimulating $\mathrm{O}_{2}^{--}$to $\mathrm{O}_{2}$ and $\mathrm{H}_{2} \mathrm{O}_{2}$ quickly and then $\mathrm{H}_{2} \mathrm{O}_{2}$ is disposed of the $\mathrm{H}_{2} \mathrm{O}_{2}$-scavenging enzyme CAT [26], [27]. Moreover, SOD and CAT activities rose in the brain, after atrazine exposure in different periods (Fig. 2, 3). Like other organisms, fish can combat the high levels of ROS in their systems with protective ROS-scavenging enzymes such as SOD and CAT, which convert superoxide anions $\left(\mathrm{O}_{2}{ }^{-}\right)$into $\mathrm{H}_{2} \mathrm{O}_{2}$ and then into $\mathrm{H}_{2} \mathrm{O}$ and $\mathrm{O}_{2}$. Thus, it is potential that any further in the activities of these enzymes contributes to the elimination of ROS from the cell resulting by atrazine exposure. Similar finding have also been reported in other species. For example, Jin [28] reported that the various concentrations $\left(1,10,100\right.$ and $\left.1000 \mu \mathrm{g} \mathrm{L} \mathrm{L}^{-1}\right)$ of atrazine exposure induced a significant dose-dependent increase in liver (SOD and CAT) activities in zebrafish (Danio rerio). The rise in the activity of SOD and CAT in all of the low-dose groups of atrazine and chlorpyrifos may reflect a countervailing response to increased oxidative stress, as proposed by Xing [29]. Consequently, Singh [30] reported that the activities of SOD and CAT in liver of adult male rats were a great increased following atrazine administration.

The activity of AChE is another biochemical biological marker commonly used to monitor aquatic environments mainly polluted by pesticides. This enzyme can be discouraged by various kinds of agrochemicals, causing excessive-stimulation of muscle fibers and leading to palsy and even death, of animals [27]. In the present study, atrazine exposure increased caused brain AChE activity decline (Fig. 2), similar to that reported by Roex [31], indicated that AChE discourage is extensively consider as a well biomarker of exposure to organophosphorus pesticides (OP). In a work conducted by Xing [32] juveniles of common carp (Cyprinus carpio) showed inhibited AChE activity in brain and muscle after $40 \mathrm{~d}$ exposure to various atrazine concentrations (4.28, 42.8 and $\left.428 \mu \mathrm{g} \mathrm{L}^{-1}\right)$. This difference among the results obtained for zebrafish and $C$. carpio can be produced by the variations in exposure periods, the size and the type of the fish. Currently, reports on the toxicity of pesticides on AChE activity in aquatic species focused on acute toxicity, but there are few reports on sub-chronic toxicity of pesticides on AChE activity in aquatic species. Statements about the impact of atrazine on $\mathrm{AChE}$ in aquatic vertebrate species are sparse. This was because the discourage of AChE activity is connect directly with the mechanism of toxic action of OPs. Furthermore, AChE was often used as an indicator of OPs exposure and physiological impact in exposed animals [33].

\section{Conclusions}

SOD, CAT and AChE activities in brain of zebrafish were all affected by atrazine, until at low concentration, which proposed that atrazine could cause oxidative stress to fish brain. Moreover, CAT in fish brain was more sensitive to atrazine compared with SOD. The important variations of antioxidant enzyme and AChE activity may be considered as the sensitive and early biomarker to reveal the pollution impacts.

The zebrafish, Danio rerio, have the ability to bioaccumulate the herbicide atrazine in aquarium experiments. There was a rapid absorption of atrazine from water in fish tested, which means that atrazine could accumulate fast in fish. Therefore, should further attention to the residue of atrazine in fish, as well as refers from the public health point of consideration; atrazine accumulation in zebrafish has special importance because of the effects of atrazine in chronic health problems.

\section{REFERENCES}

[1] D. H. Moreno, F. Soler, M. P. Míguez, and M. P. López, "Brain acetylcholinesterase, malondialdehyde and reduced glutathione as biomarkers of continuous exposure of tench, Tinca tinca, to carbofuran 
or deltamethrin," Science of the Total Environment, 408, pp. 4976-4983, 2010

[2] M. Ramesh, R. Srinivasan, and M. Saravanan, "Effect of atrazine (Herbicide) on blood parameters of common carp Cyprinus carpio (Actinopterygii: Cypriniformes)," African Journal of Environmental Science and Technology, vol. 3, no. 12, pp. 453-458, 2009.

[3] X. Dong, L. Zhu, J. Wang, J. Wang, H. Xie, X. Hou, and W. Jia, "Effects of atrazine on cytochrome P450 enzymes of zebrafish (Danio rerio)," Chemosphere, vol. 77, pp. 404-412, 2009.

[4] C. D. Nwani, W. S. Lakra, N. S. Nagpure, R. Kumar, B. Kushwaha, and S. K. Srivastava, "Toxicity of the Herbicide Atrazine: Effects on Lipid Peroxidation and Activities of Antioxidant Enzymes in the Freshwater Fish Channa Punctatus (Bloch)," Int J Environ Res Public Health, 2010 vol. 7, no. 8, pp. 3298-3312.

[5] M. N. Wacksman, J. D. Maul, and M. J. Lydy, "Impact of Atrazine on Chlorpyrifos Toxicity in Four Aquatic Vertebrates," Arch. Environ Contam Toxicol, vol. 51, pp. 681-689, 2006.

[6] C. D. Nwani, N. S. Nagpure, R. Kumar, B. Kushwaha, R. Kumar, and W. S. Lakra, "Lethal concentration and toxicity stress of Carbosulfan, Glyphosate and Atrazine to freshwater air breathing fish Channa punctatus (Bloch)," Int Aquat Res, vol. 2, pp. 105-111, 2010.

[7] WHO (1996), Guidelines for drinking-water quality, 2nd ed, "Health criteria and other supporting information," World Health Organization, Geneva, 1996, vol. 2, pp. 94

[8] S. Y. Hussein, M. A. E. Nasser, and S. M. Ahmed, "Comparative Studies on the Effects of Herbicide Atrazine on Freshwater Fish Oreochromis niloticus and Chrysichthyes auratus at Assiut, Egypt," Bull Environ Contam Toxicol, vol. 57, pp. 503-510, 1996

[9] O. A. Sánchez, L. C. Paraíba, C. M. Jonsson, and J. M. Carrasco, "Acute Toxicity and Bioconcentration of Fungicide Tebuconazole in Zebrafish (Danio rerio)," Environmental Toxicology, 2011.

[10] S. Abdullah, M. Javed, S. Yaqub, and N. Ahmad, "Metal Bioaccumulation Patterns in Major Carps during Acute Toxicity Tests," Int. J. Agric. Biol., vol. 13, no. 5, pp. 756-760, 2011.

[11] (PHG) Public Health Goal for Atrazine in Drinking Water, Office of Environmental Health Hazard Assessment California Environmental Protection Agency, 1999, pp. 51.

[12] P. P. Kulluru, B. S. Das, and R. K. Panda, "Evaluation of Sorption and Leaching Potential of Malathion and Atrazine in Agricultural Soils of India," Int. J. Environ. Res., vol. 4, no. 1, pp.75-90, 2010.

[13] D. J. Finney, Probit Analysis, 3d Ed, Cambridge University Press, 1971.

[14] C. Zhao, B. Liu, J. Wang, N. Li, Z. Qin, and L. Qiu, "Acute toxicity and bioconcentration of pyrimorph in zebrafish, Brachydanio rerio," Pest Management Science, vol. 67, no. 9, pp. 1178-1183, 2011.

[15] L. George, K. Ellman, and A. Valentino, "A new and rapid colorimetric determination of acetylcholinesterase activity," Biochemical Pharmacology, vol. 7, pp. 88-95, 1961

[16] Z. Can, "Toxic effects of Butyl-Benzyl phthalate on Zebrafish and cloning, Expression of Acetylcholinesterase Gene," A thesis of M.S. Degree in Biochemical and Molecular Biology, College of Life Science, Central Normal University, China, 2011

[17] M. M. Bradford, "A rapid and sensitive assay of protein utilizing the principle of dye binding, Analytical Biochemistry," vol. 72, pp. 248-254, 1971

[18] T. Kondo, H. Yamamoto, N. Tatarazako, K. Kawabe, M. Koshio, N. Hirai, and M. Morita, "Bioconcentration factor of relatively low concentrations of chlorophenols in Japanese medaka," Chemosphere, vol. 61, pp. 1299-1304, 2005

[19] M. A. Rahman, H. Hasegawa, and R. P. Lim, "Bioaccumulation, biotransformation and trophic transfer of arsenic in the aquatic food chain," Environmental Research, vol. 116, pp. 118-135, 2012.

[20] V. C. Jara, C. Lorenz, S. Pflugmacher, G. Nützmann, W. Kloas, and C. Wiegand, "Molecular effects and bioaccumulation of levonorgestrel in the non-target organism Dreissena polymorpha," Environmental Pollution, pp. 1-7, 2010.

[21] S. Meng, J. Chen, W. Wu, G. Hu, J. Qu, and Y. You, "Effect of Atrazine on Antioxidant Enzyme and Its Bioaccumulation in Kidney of Crucian Carp, Carassius auratus," Journal of Northeast Agricultural University (English Edition), vol. 18, no. 3, pp. 16-21, 2011

[22] H. H. D. Preez and J. H. V. Vuren, "Bioconcentration of atrazine in the banded tilapia, Tilapia sparrmanii," Comp Biochem Physiol C., vol. 101, no. 3, pp. 651-655, 1992.
[23] A. E. Jacomini, W. E. P. Avelar, A. S. M. Martinêz, and P. S. Bonato, "Bioaccumulation of Atrazine in Freshwater Bivalves Anodontites trapesialis (Lamarck, 1819) and Corbicula fluminea (Müller, 1774)," Arch Environ Contam Toxicol, vol. 51, pp. 387-391, 2006.

[24] G. Nussey, J. H. J. V. Vuren, and H. H. D. Preez, "Bioaccumulation of chromium, manganese, nickel and lead in the tissues of the moggel, Labeo umbratus (Cyprinidae), from Witbank Dam, Mpumalanga," Water SA, vol. 26, no. 2, pp. 269-284, 2000.

[25] J. R. Osten, A. O. Arana, L. Guilhermino, and A. M. V. M. Soares, "In vivo evaluation of three biomarkers in the mosquitofish (Gambusia yucatana) exposed to pesticides," Chemosphere, vol. 58, pp. 627-636, 2005.

[26] Y. Zhang, D. Meng, Z. Wang, H. Guo, Y. Wang, X. Wang, and X Dong, "Oxidative stress response in atrazine-degrading bacteria exposed to atrazine," Journal of Hazardous Materials, vol. 229-230, pp. 434-438, 2012

[27] T. G. Santos and C. B. R. Martinez, "Atrazine promotes biochemical changes and DNA damage in a Neotropical fish species," Chemosphere, vol. 89, pp. 1118-1125, 2012.

[28] Y. Jin, X. Zhang, L. Shu, L. Chen, L. Sun, H. Qian, W. Liu, and Z. Fu, "Oxidative stress response and gene expression with atrazine exposure in adult female zebrafish (Danio rerio)," Chemosphere, vol. 78, pp. 846-852, 2010.

[29] H. Xing, S. Li, Z. Wang, X. Gao, S. Xu, and X. Wang, "Histopathological changes and antioxidant response in brain and kidney of common carp exposed to atrazine and chlorpyrifos," Chemosphere, vol. 88, pp. 377-83, 2012.

[30] M. Singh, R. Sandhir, and R. Kiran, "Effects on antioxidant status of liver following atrazine exposure and its attenuation by vitamin E," Experimental and Toxicologic Pathology, vol. 63, pp. 269-276, 2011.

[31] E. W. M. Roex, R. Keijzers, and C. A. M. V. Gestel, "Acetylcholinesterase inhibition and increased food consumption rate in the zebrafish, Danio rerio, after chronic exposure to parathion," Aquatic Toxicology, vol. 64, no. 4, pp. 451-460, 2003

[32] H. Xing, J. Wang, J. Li, Z. Fan, M. Wang, and S. Xu, "Effects of atrazine and chlorpyrifos on acetylcholinesterase and Carboxylesterase in brain and muscle of common carp," Environmental Toxicology and Pharmacology, vol. 30, pp. 26-30, 2010.

[33] H. Xing, H. Wu, G. Sun, Z. Zhang, S. Xu, and S. Li, "Alterations in activity and mRNA expression of acetylcholinesterase in the liver, kidney and gill of common carp exposed to atrazine and chlorpyrifos," Environmental Toxicology and Pharmacology, vol. 35, pp. 47-54, 2013.

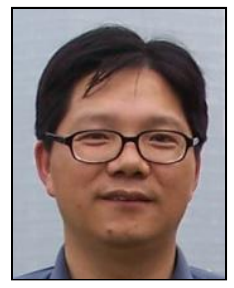

Yan Yunjun was born at Luotian County, Hubei Province, P. R. China, on September, 1969. B.S.in biology, Central China Normal University, Wuhan City. He got M.S. in zoology, Central China Normal University, Wuhan City in 1993. He got Ph.D. in hydrobiology, Institute of Hydrobiology, the Chinese Academy of Sciences, Wuhan City, P. R. China in 1995. He was professor of Biotechnology and from 1998 to2002. He is Vice Dean of College of Life Sciences and Technology, College of Life Sciences and Technology, Huazhong University of Science and Technology; 1037, Luoyu Road, Hongshan District, Wuhan 430074, P. R. China from 2012 still now. Prof. Yan is Senior committee member of the Chinese Society of Biological Engineering and Chinese Society of Microbiology. He holds a Second-grade Award from China Medical Association in 2009, and from Journal "Chinese Journal of Biotechnology" in 2009 and 2011

Abeer Ghazie A. Al-Sawafi was born at Basrah city, Iraq, on 6 June, 1978. He got B.S. in biology department, Science College, in 2000 and M.S. in Environmental pollution, biology department, Science College, Basrah University, Iraq, 2005. Now, He is getting Ph.D. Candidate, College of Life Science and Technology, Huazhong University of Science and Technology, Wuhan City, P. R. China from 2001 to 2013. She is Lecturer in Environmental and Pollution Engineering Department, Technical College, Foundation of Technical Education, Iraq. 